\title{
Adsorptive Removal of Manganese (II) from Aqueous Solution using Graphene Oxide: A Kinetics and Thermodynamics Study
}

\author{
ANEK SUDDAI, PRAWIT NUENGMATCHA and SAKSIT CHANTHAI* \\ Materials Chemistry Research Center, Department of Chemistry and Center of Excellence for \\ Innovation in Chemistry, Faculty of Science, Khon Kaen University, Khon Kaen 40002, Thailand. \\ ${ }^{*}$ Corresponding author E-mail: sakcha2@ @ku.ac.th \\ http://dx.doi.org/10.13005/ojc/330435
}

(Received: April 07, 2016; Accepted: November 11, 2016)

\begin{abstract}
An excess amount of manganese is known to affect neurological toxicity. This study focused on adsorptive removal of $\mathrm{Mn}$ (II) using graphene oxide, which was carried out under optimum conditions after varying some experimental effects including $\mathrm{pH}$, an incubation time and an initial concentration. It was demonstrated that $\mathrm{Mn}$ (II) adsorption follows both Langmuir and Freundlich isotherms. The maximum adsorption capacity for $\mathrm{Mn}(\mathrm{II})$ removal from an aqueous solution was 41.67 $\mathrm{mg} / \mathrm{g}$ at $\mathrm{pH} 5$ and their adsorption state was completed within $30 \mathrm{~min}$. The adsorption kinetics was in accordance with pseudo second-order kinetic model. In thermodynamics diversion, changes in free energy, enthalpy and entropy were also studied. Overall, the adsorption process was exothermic and spontaneous in nature.
\end{abstract}

Keywords: Graphene oxide; Manganese; Adsorption isotherm;

Thermodynamics; Kinetics

\section{INTRODUCTION}

Manganese $(\mathrm{Mn})$ is an abundant element in the Earth's crust and its presence in water is a result of leaching process. ${ }^{1}$ Although $\mathrm{Mn}$ is an essential nutrient element in living systems, an excess of $\mathrm{Mn}$ can result in toxic neurological effects, and there are many neurotoxic effects that cause a series of symptoms. ${ }^{2-4}$ Therefore, it is necessary to remove $\mathrm{Mn}$ (II) contaminants particularly from wastewater before it is released back to the environment. The adsorption process is one of the most promising for removal of metal ions. However, several carbonbased adsorbents for metal removal from wastewater are still limited in their use because of low efficiency and adsorption capacity. In order to improve capacity and selectivity of the adsorption, new adsorbents have been developed. Among these, graphene oxide (GO) is increasingly used as a new choice for carbon-based adsorbents. There are many applications of $\mathrm{GO}$ for removal from water samples of toxic metals and dye pollutants such as $\mathrm{Hg}(\mathrm{II}),{ }^{5}$ $\mathrm{Pb}(\mathrm{II}),{ }^{6} \mathrm{As}(\mathrm{V}),{ }^{7} \mathrm{Cd}(\mathrm{II}),{ }^{8} \mathrm{Cr}(\mathrm{VI}),{ }^{9} \mathrm{Co}(\mathrm{II}),{ }^{10}$ malachite green ${ }^{11}$ and alizarin red $\mathrm{S}^{12}$. However, there have 
not been reports of its use on the removal of $\mathrm{Mn}$ (II) from aqueous solution.

In this study, GO was applied to remove $\mathrm{Mn}$ (II) from aqueous solution. Potential use of GO for Mn(II) removal in a batch adsorption study was compared with that of other carbon-based adsorbents. The effects of $\mathrm{pH}$, an incubation time and an initial concentration of $\mathrm{Mn}$ (II) were optimized. Langmuir and Freundlich isotherms were also investigated in detail to fit its adsorption model. Both kinetics and thermodynamics aspects were also investigated to find out the adsorption behaviour for $\mathrm{Mn}(\mathrm{II})$ from aqueous solution.

\section{MATERIALS AND METHODS}

\section{Preparation of graphene oxide}

In this work, graphene oxide was prepared from commercial graphite following a protocol described in our previous work. ${ }^{13}$ Briefly, $3.0 \mathrm{~g}$ of graphite, $300 \mathrm{~mL}$ of $98 \% \mathrm{H}_{2} \mathrm{SO}_{4}, 23.0 \mathrm{~g}$ of $\mathrm{KMnO}_{4}$ and $3.0 \mathrm{~g}$ of $\mathrm{NaNO}_{3}$ were mixed under cold condition $\left(0^{\circ} \mathrm{C}\right)$ in an ice bath. After a 30-min stirring, a slow addition of $200 \mathrm{~mL}$ of deionized water to the mixture followed. The mixture was subject to another $30 \mathrm{~min}$ of stirring and then heated to $80{ }^{\circ} \mathrm{C}$ for $6 \mathrm{~h}$ before an addition of $40 \mathrm{~mL}$ of $30 \% \mathrm{H}_{2} \mathrm{O}_{2}$. We used deionized water to wash the mixture several times until the filtrate $\mathrm{pH}$ reached neutral at which point lyophilized precipitates could be obtained.

\section{Adsorption experiment}

The adsorption experiment of $\mathrm{Mn}(\mathrm{II})$ was performed using batch technique. Graphene oxide (0.02 g) was accurately weighed into a $125 \mathrm{~mL}$ conical flask followed by an addition of $25 \mathrm{~mL}$ of $\mathrm{Mn}$ (II) solution (10 mg/L). $\mathrm{pH}$ of the solution was adjusted. At room temperature $\left(30^{\circ} \mathrm{C}\right)$ and at approximately $200 \mathrm{rpm}$, the solution was subjected to shaking by an orbital shaker. To determine the optimum conditions for maximum adsorption capacity $\left(q_{m}\right)$ of $\mathrm{GO}$, various experimental parameters were considered including
$\mathrm{pH}$ of solution (1-6), an incubation time (1-50 min), and an initial concentration of $\mathrm{Mn}$ (II) (2-30 mg/L). After a period of shaking, we subjected the mixed solution to 5 min of centrifugation to separate the absorbent. AAS was used to determine $\mathrm{Mn}$ (II) in the supernatant solution. We conducted our all of our experiments in triplicate with the same experimental conditions. An equation below was used to determine the adsorption capacity $\left(q_{e}, \mathrm{mg} / \mathrm{g}\right)$ of $\mathrm{Mn}(\mathrm{II})$ at an equilibrium state,

$q_{e}=\frac{V\left(C_{o}-C_{e}\right)}{m}$

where, $C_{o}, C_{e}, V$ and $m$ are the initial $\mathrm{Mn}(\mathrm{II})$ concentration (mg/L) of the solution, $\mathrm{Mn}(\mathrm{II})$ concentration at the equilibrium state, the solution volume $(\mathrm{L})$ and the adsorbent mass $(\mathrm{g})$, respectively. To describe the equilibrium nature of $\mathrm{Mn}$ (II) adsorption onto the adsorbent, Langmuir and Freundlich adsorption models were also studied.

\section{RESULTS AND DISCUSSION}

\section{Optimum conditions for $\mathrm{Mn}$ (II) removal}

Fig. 1(a) shows the effect of $\mathrm{pH}$ on the adsorption capacity. The $\mathrm{pH}$ value was adjusted by acetate buffer solution $(\mathrm{pH} 1-5)$ and phosphate buffer solution ( $\mathrm{pH} 6)$. The results showed that the adsorption capacity of $\mathrm{Mn}$ (II) dramatically increased with the solution at $\mathrm{pH} \mathrm{1-4} \mathrm{and} \mathrm{was} \mathrm{constant} \mathrm{in} \mathrm{the}$ $\mathrm{pH}$ range of 5-6. The maximum adsorption capacity was at $\mathrm{pH} 5(3.14 \mathrm{mg} / \mathrm{g})$. The $\mathrm{pH}$ value at the point of zero charge $\left(\mathrm{pH}_{\mathrm{PzC}}\right)$ of $\mathrm{GO}$ has been previously reported to be $4.1^{11}$. At $\mathrm{pH}$ lower than $\mathrm{pH}_{\mathrm{PzC}}$, the adsorption capacities of GO were lower due to the fact that under acidic solution, the surface GO surface was positively charged and did not favor an uptake of $\mathrm{Mn}(\mathrm{II})$. Whereas, at $\mathrm{pH}$ higher than $\mathrm{pH}_{\mathrm{PZC}}$, the adsorbents' surface became negatively charged facilitating the uptake of $\mathrm{Mn}(\mathrm{II})$. As a result, we found that we had the maximum adsorption capacity of GO at $\mathrm{pH}$ higher than 5 .

Table 1: Thermodynamic data of Mn(II) adsorption using GO as an adsorbent

\begin{tabular}{|c|c|c|c|c|c|c|}
\hline \multirow[t]{2}{*}{$\Delta H^{0}(\mathrm{~kJ} / \mathrm{mol})$} & \multirow[t]{2}{*}{$\Delta \mathbf{S}^{0}(\mathrm{~kJ} / \mathrm{mol} . \mathrm{K})$} & \multicolumn{4}{|c|}{$\Delta \mathrm{G}^{0}(\mathrm{~kJ} / \mathrm{mol})$} & \multirow[t]{2}{*}{$\mathbf{R}^{2}$} \\
\hline & & $303 \mathrm{~K}$ & $313 \mathrm{~K}$ & $323 \mathrm{~K}$ & $333 \mathrm{~K}$ & \\
\hline-8.08 & -7.03 & -23.69 & -23.30 & -24.17 & -25.01 & 0.8040 \\
\hline
\end{tabular}



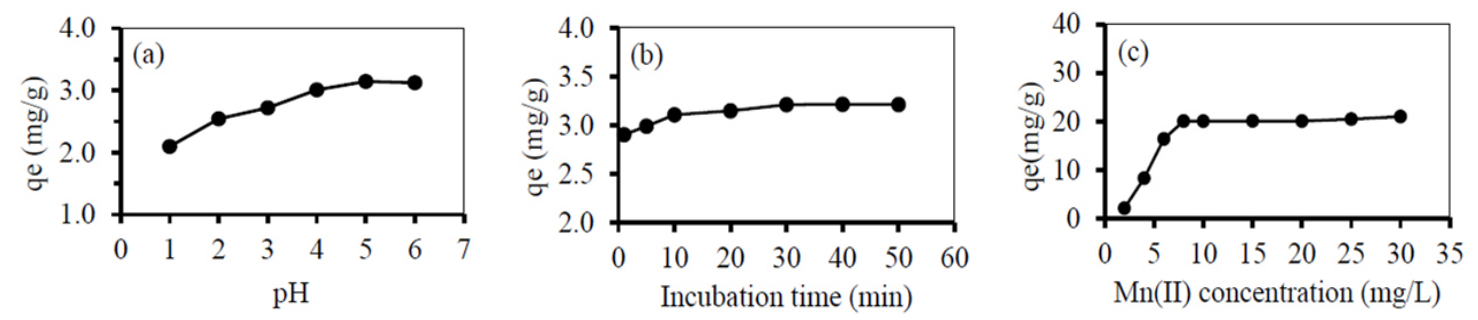

Fig. 1: Effects of (a) pH, (b) an incubation time and (c) an initial concentration of $\mathrm{Mn}$ (II)

Table 2: The kinetic parameters of Mn(II) adsorption using GO

\begin{tabular}{lllllll}
\hline $\boldsymbol{q}_{e, \text { exp }}(\mathrm{mg} / \mathrm{g})$ & \multicolumn{2}{l}{ Pseudo-first order } & \multicolumn{2}{l}{ Pseudo-second order } & \multicolumn{2}{l}{ Intra-particle diffusion } \\
\hline \multirow{3}{*}{3.28} & $\mathrm{q}_{\mathrm{e}}(\mathrm{mg} / \mathrm{g})$ & 1.09 & $\mathrm{q}_{\mathrm{e}}(\mathrm{mg} / \mathrm{g})$ & 3.33 & $\mathrm{k}_{\mathrm{p}}\left(\mathrm{mg} / \mathrm{g} \cdot \mathrm{min}^{1 / 2}\right)$ & 0.11 \\
& $\mathrm{k}_{1}(\mathrm{~min})$ & 0.15 & $\mathrm{k}_{2}(\mathrm{~g} / \mathrm{mg} \cdot \mathrm{min})$ & 0.38 & $\mathrm{C}(\mathrm{mg} / \mathrm{g})$ & 2.65 \\
& $\mathrm{R}^{2}$ & 0.9936 & $\mathrm{R}^{2}$ & 0.9999 & $\mathrm{R}^{2}$ & 0.9915 \\
\hline
\end{tabular}

The effect of incubation time of $\mathrm{Mn}(\mathrm{II})$ adsorption onto the $\mathrm{GO}$ with $10 \mathrm{mg} / \mathrm{L}$ of the initial $\mathrm{Mn}$ (II) concentration at $\mathrm{pH} 5$ is shown in Figure 1(b). It can be well seen that at the beginning the rate of adsorption went up with increasing incubation time with equilibrium time observed within $30 \mathrm{~min}$. We, therefore, subjected our further experiments with an incubation time of 30 min. Figure 1 (c) shows the equilibrium adsorption capacity plotted against the initial concentration of $\mathrm{Mn}$ (II). It is demonstrated that the equilibrium adsorption capacity increased with increasing initial concentration. At $\mathrm{Mn}$ (II) concentration of $8 \mathrm{mg} / \mathrm{L}$, the maximum equilibrium adsorption capacity of $20.03 \mathrm{mg} / \mathrm{g}$ was reached. Higher collision probability between $\mathrm{Mn}$ (II) and the adsorbent particles together with yet-to-be-occupied active sites on the GO surface likely contributed to the initial increase in the uptake capacity of GO when an initial $\mathrm{Mn}$ (II) concentration was increased.

\section{Thermodynamic study}

For thermodynamic study, the calculations of Gibbs free energy change $\left(\Delta G^{0}\right)$, entropy change $\left(\Delta S^{0}\right)$ and enthalpy change $\left(\Delta \mathrm{H}^{0}\right)$ were performed using the following equations:

$$
\begin{aligned}
& \Delta G^{\circ}=-R T \ln K_{d} \\
& K d=\frac{q_{e}}{C e}
\end{aligned}
$$

$$
\ln K d=-\frac{\Delta H^{\circ}}{R T}+\frac{\Delta S^{\circ}}{R}
$$

where, $R$ is the constant $(8.314 \mathrm{~J} / \mathrm{mol} \mathrm{K}), T$ is absolute temperature in $\mathrm{K}$ and $K_{d}$ is the equilibrium constant. $q_{e}$ is the amount of the $\mathrm{Mn}$ (II) at equilibrium $(\mathrm{mg} / \mathrm{g}), C_{e}$ is the equilibrium concentration $(\mathrm{mg} / \mathrm{L})$ of $\mathrm{Mn}(\mathrm{II})$ in the solution.

The slope and the intercept of the van't Hoff plot of In $K_{d}$ versus 1/T, were used for the calculation of $\Delta \mathrm{S}^{0}$ and $\Delta \mathrm{H}^{0}$, respectively (Fig. 2). Table 1 summarizes the thermodynamic data.

From Table 1, the negative value of $\Delta G^{0}$ indicates that the ongoing adsorption process is spontaneous ${ }^{14}$. The negative $\Delta \mathrm{H}^{0}$ indicates that the adsorption of the metal by $\mathrm{GO}$ is exothermic in nature; while, the negative value of $\Delta S^{\circ}$ indicates that during adsorption there is a tendency for lower disorder at the solid-solution interface ${ }^{15}$. The boundary layer becomes thinner at higher temperatures because metal molecules tend to escape from the adsorbent surface to its bulk solution, lowering the adsorption capacity when the temperature goes up ${ }^{16}$.

\section{Kinetic study}

To understand the nature of the adsorption phenomenon in terms of the order of the rate constant, three kinetic models were applied including pseudo-first order, pseudo-second-order and intra- 
particle diffusion model. These models are expressed in the following equations (Eq. (5) to Eq. (7)).

$$
\begin{aligned}
& \log \left(q_{e}-q_{t}\right)=\log q_{e}-\frac{k_{1}}{2.303} t \\
& \frac{t}{q_{t}}=\frac{1}{k_{2} q_{e}^{2}}+\frac{1}{q_{e}} t \\
& q_{t}=k_{p} t^{\frac{1}{2}}+C
\end{aligned}
$$

where, $k_{1}$ is rate constant $(\mathrm{L} / \mathrm{min})$ of pseudo-first order adsorption, $k_{2}$ is rate constant of pseudo-second-order adsorption ( $\mathrm{g} / \mathrm{mg} \mathrm{min}), k_{p}$ is an intra-particle diffusion rate constant in $\mathrm{mg} /(\mathrm{g}$ $\left.\min ^{1 / 2}\right) q_{e}$ and $q_{t}$ are the amounts of $\mathrm{Mn}(\mathrm{II})$ adsorbed onto $\mathrm{GO}$ at an equilibrium state $(\mathrm{mg} / \mathrm{g})$ and at time $t$, respectively.

For the pseudo-first order, we calculated the values of $k_{1}$ and $q_{e}$ from the slope and the intercept of the plot of $\log \left(q_{e}-q_{t}\right)$ versus $t$, respectively (Fig. $3(\mathrm{a})$ ); while, the values of $k_{2}$ and $q_{e}$ for the pseudosecond-order adsorption are calculated from the slope and the intercept of the plot of $t / q_{t}$ versus $t$,

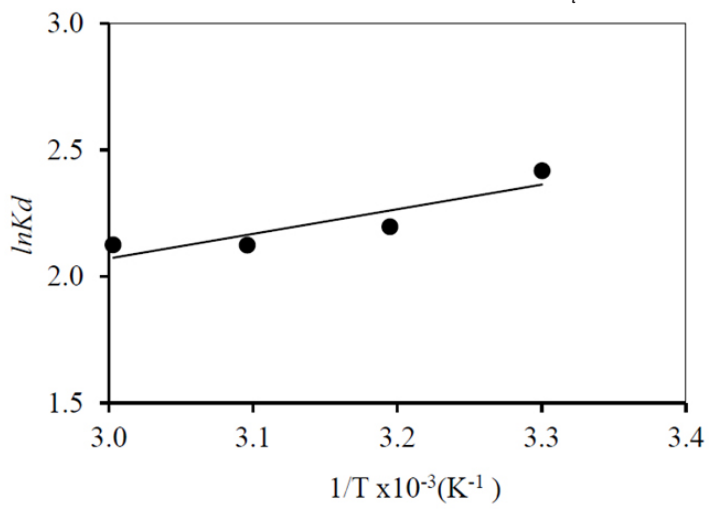

Fig. 2: Plot of In $K_{d}$ versus 1/T for $\mathrm{Mn}$ (II) adsorption using GO respectively (Fig. 3(b)). In addition, the values of $k_{p}$ and $C$ of the intra-particle diffusion were based on the calculation from the slope and the intercept of the plot of $q_{t}$ versus $t^{1 / 2}$, respectively (Fig. 3(c)). The kinetic parameters obtained from these models are summarized in Table 2.

As shown in Table 2, the pseudo-first order kinetic model could not explain the adsorption of $\mathrm{Mn}(\mathrm{II})$ using $\mathrm{GO}$, as there was a great difference between the value from the calculation of maximum adsorption capacity $\left(q_{e}=1.09 \mathrm{mg} / \mathrm{g}\right)$ and that from the experiment $\left(q_{e, \text { exp }}=3.28 \mathrm{mg} / \mathrm{g}\right)$. On the contrary, the calculated $q_{e}$ value for the pseudo-second order kinetic model $(3.33 \mathrm{mg} / \mathrm{g}$ ) was similar to that from the experiment with high linear correlation coefficient $\left(R^{2}\right)$ of 0.9999 . Therefore, the pseudo-second-order kinetic model was applicable to the adsorption of $\mathrm{Mn}(\mathrm{II})$.

\section{Adsorption isotherm}

Langmuir and Freundlich models are used to describe the adsorption isotherms. The Langmuir model assumes that an adsorbate's monolayer coversa homogenous adsorbent surface which has a finite number of the adsorption sites via uniform strategies of adsorption without any transmigration of the adsorbate occurring along the surface plane. The Freundlich adsorption isotherm assumes a heterogeneous surface energy for which the energy term in the Langmuir equation varies as a function of a surface coverage. The linear form of both Langmuir and Freundlich isotherms are given by the following Eq. (8) and Eq. (9):

$$
\begin{aligned}
& \frac{C_{e}}{q_{e}}=\frac{C_{e}}{q_{m}}+\frac{1}{q_{m} K_{L}} \\
& \log q_{e}=\log K_{F}+\frac{1}{n} \log C_{e}
\end{aligned}
$$

\begin{tabular}{|c|c|c|c|c|c|c|}
\hline \multirow[t]{2}{*}{ Adsorbent } & \multicolumn{2}{|c|}{ Langmuir isotherm } & \multicolumn{3}{|c|}{ Freundlich isotherm } & \multirow[b]{2}{*}{$\mathbf{R}^{2}$} \\
\hline & $q_{\max }(m g / g)$ & $K_{L}$ & $\mathbf{R}^{2}$ & $\mathrm{~K}_{\mathrm{F}}$ & $1 / n$ & \\
\hline Graphene oxide & 41.67 & 0.02 & 0.9765 & 2.99 & 0.88 & 0.8773 \\
\hline
\end{tabular}

Table 3: Isotherm parameters and correlation coefficients calculated for the adsorption of $\mathrm{Mn}(\mathrm{II})$ using GO 
where, $q_{m}$ is the maximum amount of $\mathrm{Mn}(\mathrm{II})$ absorbed per unit weight of adsorbent $(\mathrm{mg} / \mathrm{g})$ that forms complete monolayer on the surface at the equilibrium state of metal concentration $(\mathrm{mg} / \mathrm{L}), q_{e}$ is the amount of $\mathrm{Mn}(\mathrm{II})$ adsorbed per unit weight of adsorbent at equilibrium, and $K_{L}$ is the Langmuir constant $(\mathrm{L} / \mathrm{mg}), K_{F}$ and $\mathrm{n}$ are the Freundlich constant and the intensity of adsorption, respectively.

The values of $q_{m}$ and $K_{L}$ are calculated from the slope and the intercept of the straight line plot of $C_{e} / q_{e}$ versus $C_{e}$, respectively (Fig. 4(a)). The values of $K_{F}$ and $1 / \mathrm{n}$ can be obtained from a linear
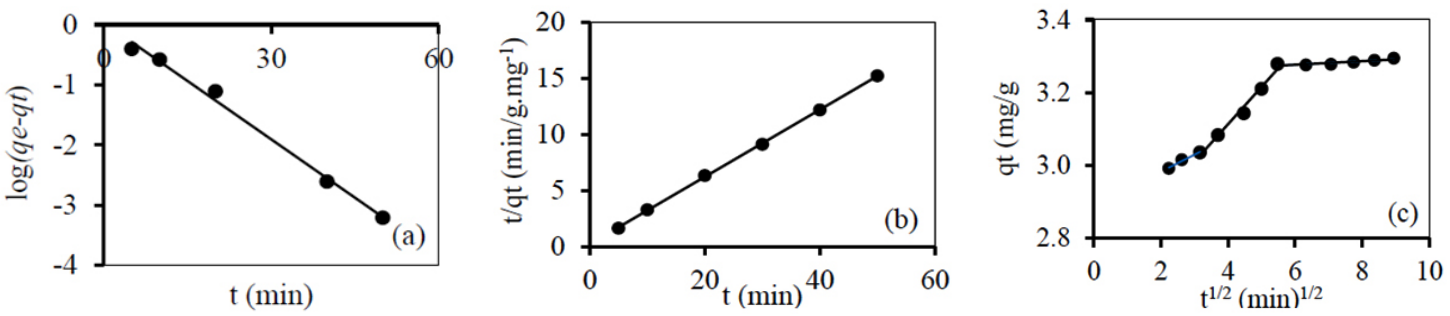

Fig. 3. (a) pseudo-first-order (b) pseudo-second-order and (c) intra-particle diffusion of Mn(II) adsorption using GO as an adsorbent
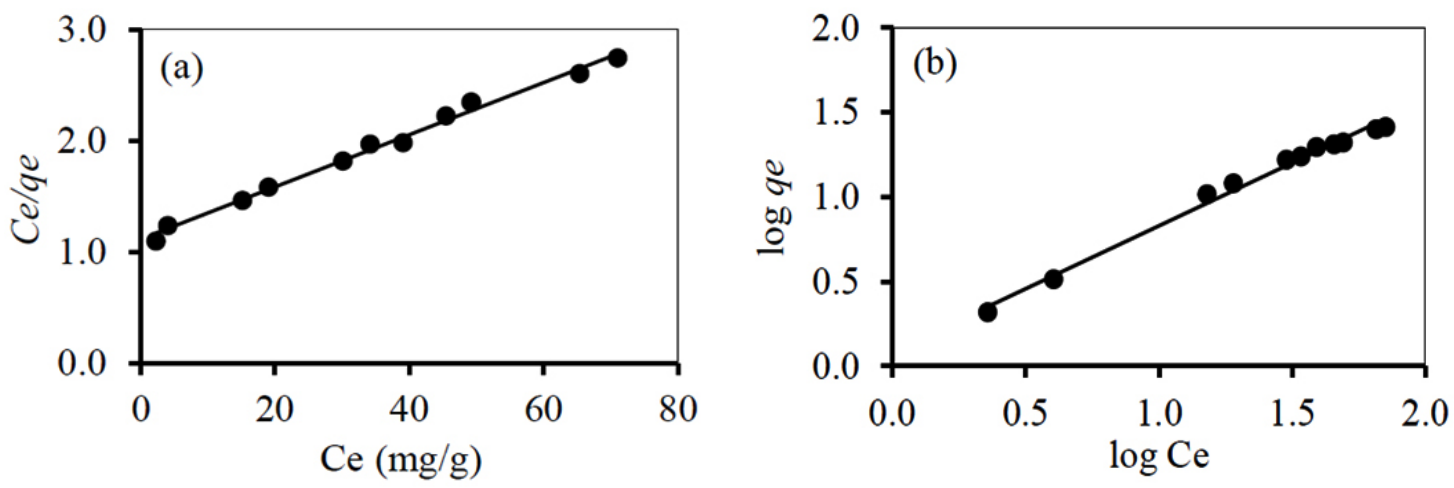

Fig. 4. (a) Langmuir and (b) Freundlich adsorption plots of Mn(II) adsorption using $\mathrm{GO}$ as an adsorbent

Table 4: Comparison of maximum adsorption capacities of $\mathrm{Mn}$ (II) using various carbon-based adsorbents

\begin{tabular}{lll}
\hline Adsorbent & $\mathbf{q}_{\mathbf{m}}(\mathbf{m g} \mathbf{g})$ & Reference \\
\hline Na-montmorillonite & 3.22 & {$[17]$} \\
Granular activated carbon & 2.54 & {$[18]$} \\
Dolomite & 2.21 & {$[19]$} \\
Activated carbon immobilized by tannic acid & 1.73 & {$[20]$} \\
Marble & 1.20 & {$[19]$} \\
Pithacelobium dulce carbon & 0.41 & {$[21]$} \\
Graphene oxide & 41.67 & This work \\
\hline
\end{tabular}


Table 4 shows the maximum adsorption capacity of $\mathrm{Mn}$ (II) using other adsorbents. In comparison with other carbon-based adsorbents, GO has by far the highest adsorption capacity for the $\mathrm{Mn}$ (II) removal from aqueous solution.

\section{CONCLUSION}

The results indicate the suitability and efficiency of graphene oxide as an adsorbent for the removal of $\mathrm{Mn}$ (II) from aqueous solution. With maximum adsorption capacity for $\mathrm{Mn}$ (II) being $41.67 \mathrm{mg} / \mathrm{g}$, it far outstrips other carbon-based adsorbents. The pseudo second-order kinetic model was applicable to the adsorption kinetics.. The intraparticle diffusion model described that the intraparticle diffusion was not the only rate-limiting step, but surface adsorption and intra-particle diffusion mechanisms worked in simultaneous corporation during adsorption. $\Delta \mathrm{G}^{0}$ indicates the spontaneity of the ongoing adsorption process; while, $\Delta S^{0}$ indicates a tendency to lower disorder at the solid-solution interface during the adsorption. In addition, the $\Delta \mathrm{H}^{0}$ indicates that the adsorption process is an exothermic nature. Our experiments clearly showed that the as-prepared GO has a high potential as adsorbent for $\mathrm{Mn}$ (II) removal.

\section{ACKNOWLEDGEMENTS}

This research study was financially supported by Materials Chemistry Research Center, Department of Chemistry and Center of Excellence for Innovation in Chemistry (PERCH-CIC), Faculty of Science, Khon Kaen University, and the Ministry of Science and Technology, Bangkok, Thailand.

\section{REFERENCES}

1. Ates, A. Powder Technol. 2014, 264, 86-95.

2. Flynn, MR.; Susi, P. Int. J. Hyg. Environ Health. 2009, 212, 459-469.

3. Michalke, B.; Fernsebner, K. J. Trace Elem. Med. Biol. 2014, 28, 106-116.

4. Dusek, P.; Roos, P.M.; Litwin, T.; Schneider, S.A.; Flaten, T.P.; Aaseth, J. J. Trace Elem. Med. Biol. 2015, 31, 193-203.

5. Nuengmatcha, P.; Mahachai, R.; Chanthai, S. Asian. J. Chem. 2014, 26, S85-S88.

6. Madadrang, C.J; Kim, H.Y.; Gao, G.; Wang, N.; Zhu, J.; Feng, H.; Gorring, M.; Kasner, M.L.; Hou, S. ACS Appl. Mater. Interfaces. 2012, 4, 1186-1193.

7. Zhang, K.; Dwivedi, V.; Chi, C.; Wu, J. J. Hazard. Mater. 2010, 182, 162-168.

8. Deng, J.H.; Zhang, X.R.; Zeng, G.M.; Gong, J.L.; Niu, Q.Y.; Liang, J. Chem. Eng. J. 2013, 266, 189-200.

9. Li, L.; Fan, L.; Sun, M.; Qiu, H.; Li, X.; Duan, H.; Luo, C. Colloids Surf., B 2013, 107, 76-83.

10. Zhao, G.; Li, J.; Ren, X.; Chen, C.; Wang, X. Environ. Sci. Technol. 2011, 45, 1045410462.
11. Nuengmatcha, P.; Mahachai, R.; Chanthai, S. Orient. J. Chem. 2014, 30, 1463-1474.

12. Nuengmatcha, P. ; Mahachai, R.; Chanthai, S. Orient. J. Chem. 2016, 32, 1399-1410.

13. Nuengmatcha, P.; Mahachai, R.; Chanthai, S. Asian. J. Chem.2014, 26, 1321-1323.

14. Haghdoost, G. Orient. J. Chem. 2016, 32(3), 1485-1492.

15. Hadavifar, M.; Bahramifar, N.; Younesi, H.; Li, Q. Chem. Eng. J. 2014, 237, 217-228.

16. Saha, P.; Chowdhury, S.; Gupta, S.; Kumar, I. Chem. Eng. J. 2010, 165, 874-882.

17. Abollino, O.; Aceto, M.; Malandrino, M.; Sarzanini, C.; Mentasti, E. Water Res. 2003, 37, 1619-1627.

18. Jusoh, A.B.; Cheng, W.H.; Low, W.M.; Nora'aini, A.; Noor, M.J.M.M. Desalination. 2005, 182, 347-353.

19. Kroik, A.A.; Shramko, O.N.; Belous, N.V. Chem. Technol. Water. 1999, 21, 310-314.

20. çer, A.-.; Uyanik, A.; Aygün, S.F. Sep. Purif. Technol. 2006, 47, 113-118.

21. Emmanuela, K.A.; Veerabhadra Rao, A. Rasayan J. Chem. 2008, 1, 840-852. 